\title{
Anticorpos anti-Brucella canis e anti-Brucella abortus em cães de Araguaína, Tocantins
}

\author{
Antibodies anti-Brucella canis and anti-Brucella abortus in dogs from Araguaína, Tocantins, \\ Brazil
}

\author{
Elaine Maria Seles DORNELES ${ }^{1}$; Helcileia SANTOS ${ }^{2}$; Silvia MINHARRO²; Josefa Moreira do \\ NASCIMENTO-ROCHA ${ }^{2}$; Luis Antônio MATHIAS ${ }^{3}$; Maurício Gauterio DASSO ${ }^{4}$; Carolina Daros \\ TIENSOLI ${ }^{1}$; Marcos Bryan HEINNEMAN ${ }^{1}$; Andrey Pereira LAGE ${ }^{1}$
${ }^{1}$ Laboratório de Bacteriologia Aplicada do Departamento de Medicina Veterinária Preventiva da Escola de Veterinária da Universidade Federal de Minas Gerais, Belo Horizonte-MG, Brasil
${ }^{2}$ Escola de Medicina Veterinária e Zootecnia da Universidade Federal do Tocantins, Araguaína-TO, Brasil Universidade Estadual Paulista, Jaboticabal-SP, Brasil
${ }^{4}$ Instituto de Pesquisas Veterinárias Desidério Finamor, Eldorado do Sul-RS, Brasil \\ ${ }^{3}$ Departamento de Medicina Veterinária Preventiva e Reprodução Animal da Faculdade de Ciências Agrárias e Veterinárias da
}

\begin{abstract}
Resumo
Os objetivos deste estudo foram determinar a soroprevalência da infecção por Brucella canis e Brucella abortus e avaliar os possíveis fatores de risco associados à infecção em cães no município de Araguaína, Tocantins. Soros de 374 cães, pertencentes à zona urbana do município de Áraguaína-Tocantins, foram analisados pelas técnicas de imunodifusão em ágar gel (IDGA), para pesquisa de anticorpos contra Brucella canis, e antígeno acidificado tamponado (AAT) e polarização fluorescente (FPA) para detecção de anticorpos contra Brucella abortus. Dos 374 soros testados para presença de anticorpos contra B. abortus, 21 foram reagentes no AAT, entretanto todos foram negativos pela FPA. À prova do IDGA 167 animais foram reagentes resultando em uma prevalência para B. canis de 44,53\% (IC 95\%; 39,43 a 49,72). A avaliação de possíveis fatores de risco associados à soropositividade para $B$. canis não revelou a existência de relação entre a infecção e as variáveis individuais estudadas. Assim, o presente estudo permite concluir que não houve animais infectados por B. abortus e que a infecção por B. canis está disseminada nos cães do município de Araguaína, Tocantins.
\end{abstract}

Palavras-chave: Brucelose canina. Epidemiologia. Brasil. Imonodifusão em ágar gel.

\begin{abstract}
The aims of the present study were to determine the seroprevalence of infection by Brucella canis and Brucella abortus and to evaluate possible risk factors for infection in dogs from Araguaína, Tocantins, Brazil. Sera from 374 dogs, of the urban zones of the municipality, from both sexes, were submitted to the agar-gel immunodiffusion for Brucella canisantibodies and to rose Bengal test (AAT) and fluorescence polarization assay (FPA) for Brucella abortus-antibodies. From the 374 tested dogs, 21 reacted in the AAT, but no one was positive in the FPA. The seroprevalence of $B$. canis infection found in Araguaína, Tocantins, Brazil, was 44.53\% (95\% IC; 39.43 to 49.72). No association was found among seropositivity for $B$. canis and the risk factors studied. Thus, data from the present study showed that there was no infection by $B$. abortus among dogs in the sample and that infection by $B$. canis is widespread and at high prevalence in Araguaína, Tocantins, Brazil.
\end{abstract}

Keywords: Canine brucellosis. Epidemiology. Brazil. Agar-gel immunodiffusion.

A brucelose canina é uma enfermidade infectocontagiosa, que causa aborto e infertilidade nas fêmeas e epididimite e atrofia testicular nos machos. Pode acometer também canídeos silvestres, o homem e raramente gatos $^{1,2}$. A infecção, na grande maioria dos casos, é ocasionada pela Brucella canis, no entanto a Brucella abortus pode estar envolvida ${ }^{3}$. Desde a sua descrição nos Estados Unidos em $1966^{4}$, a doença já foi comprovada em vários países, podendo-se afirmar que está mundialmente distribuída ${ }^{2}$.

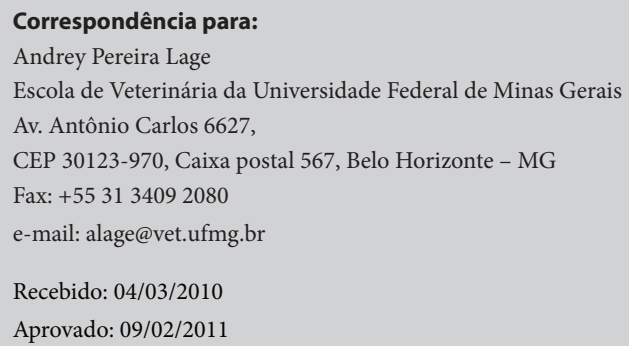


No Brasil, inquéritos sorológicos identificaram a presença de anticorpos contra os agentes da brucelose canina em vários locais, com frequências variando de 0,84\% a 58,3\%, mostrando que a doença é prevalente no país e responsável por problemas reprodutivos nos cães, com inúmeros prejuízos aos criadores, e possível fonte para infecções humanas $3,5,6,7,8,9,10,11,12,13$.

Considerando-se o caráter zoonótico da brucelose canina, sua interferência na vida reprodutiva do animal e a grande inserção dos cães na sociedade, o objetivo deste estudo foi determinar a prevalência da infecção por Brucella canis e Brucella abortus em cães no município de Araguaína, Tocantins, e avaliar os possíveis fatores de risco associados a essas infecções.

O inquérito epidemiológico foi conduzido no segundo semestre de 2005 durante a campanha de vacinação antirrábica do Município de Araguaína, Tocantins, em parceria com o Centro de Controle de Zoonoses (CCZ) da Prefeitura Municipal de Araguaína. O número de animais necessário ao ensaio foi calculado estimando-se uma prevalência de $50 \%$, com intervalo de confiança de $95 \%$ e um erro de $5 \%{ }^{14}$, resultando em uma amostra de 374 animais. A coleta foi realizada em 54 postos de vacinação, distribuídos em bairros da zona urbana do município. O número de animais amostrados por posto foi proporcional ao número de animais estimado para atendimento pelo CCZ (11870 cães), sendo coletada uma amostra a cada 10 animais vacinados. Sangue de 373 cães, de ambos os sexos, foi coletado por punção da veia cefálica e os soros foram separados e estocados a $-20^{\circ} \mathrm{C}$ até o momento das análises. Para cada animal foi preenchida uma ficha de identificação contendo dados individuais (idade) e informações referentes a hábitos e vida reprodutiva (acesso à rua, contato com outros animais, castração e acasalamento).

A pesquisa de anticorpos contra Brucella canis foi realizada pela técnica de imunodifusão em ágar gel (IDGA), segundo Souza et al. ${ }^{10}$, empregando-se an- tígeno solúvel de Brucella ovis (Instituto de Pesquisas Veterinárias Desidério Finamor - IPVDF, Brasil). Para a pesquisa de anticorpos anti-Brucella abortus, empregou-se, como triagem, o teste do antígeno acidificado tamponado (AAT) (Instituto de Tecnologia do Paraná - TECPAR, Brasil) e, como teste confirmatório, a prova de polarização fluorescente [FPA ("Brucella abortus antibody test kit -Brucella FPA"), Diachemix, USA] ${ }^{15,16,17}$.

Os dados sorológicos, a prevalência, o intervalo de confiança e as associações foram calculados e analisados segundo Noordhuizen et al. ${ }^{14}$. O cálculo das associações entre a soropositividade e as variáveis referentes a características individuais e hábitos dos animais foi realizado por meio de análise univariada, utilizando-se os testes de qui-quadrado e exato de Fisher, empregando-se um erro $a$ de $0,05^{18}$. Todas as análises estatísticas foram realizadas empregando o software EPI-Info 6.04 ${ }^{19}$.

Dos 374 soros pesquisados para presença de anticorpos séricos contra $B$. abortus, 21 aglutinaram no AAT, entretanto todos foram negativos pela FPA. À IDGA para B. canis foram encontrados 167 cães positivos em $96,29 \%$ dos postos de vacinação, o que resultou em prevalência de 44,53\% (IC95\%: 39,43 a 49,72). As evidências sorológicas indicam que a prevalência de infecção por $B$. canis é alta e está disseminada nos cães do município de Araguaína, Tocantins. Os dados relativos à prevalência de brucelose canina no Brasil são variáveis e as comparações com o presente estudo são dificultadas em decorrência de diferenças de delineamento amostral e ensaios sorológicos empregados ${ }^{3}$. Utilizando antígenos de superfície, o teste de IDGA, pode apresentar problemas de reação cruzada com outros microrganismos, além de dificuldades de interpretação ${ }^{20}$. Considerando estes aspectos, alguns trabalhos têm mostrado a ocorrência de resultados falsos positivos, sobretudo quando se utiliza antígenos de superfície como o LPS ${ }^{21,22}$ De modo contrário, a imunodifusão em ágar gel empregando 
antígenos intracitoplasmáticos é um método com especificidade de $100 \%$, apesar de poder apresentar problemas de sensibilidade diagnóstica com uma proporção significativa de resultados falso-negativos, sobretudo, em infecções recentes ${ }^{20,23}$. Discrepâncias na sensibilidade e especificidade diagnóstica do teste de IDGA podem ser observadas em função de diferentes estirpes, protocolos ou antígenos empregados na prova. No entanto, ainda considerando-se esses pontos, a soroprevalência de $B$. canis encontrada em cães de Araguaína está entre as mais elevadas. Ademais, como o teste de IDGA empregado possui boa especificidade, mas pode apresentar problemas de sensibilidade diagnóstica em algumas situações ${ }^{20}$, a prevalência real pode ser superior à estimada.

A análise de todas as variáveis levantadas como possíveis fatores de risco para $B$. canis não revelou a exis- tência de associação entre estas e a soropositividade, os resultados estão sumarizados na tabela 1. A inexistência de associação estatística entre as características individuais dos animais e a infecção por B. canis também foi observada em outros estudos realizados no Brasil ${ }^{12,24,25}$. A alta prevalência de infecção por $B$. canis encontrada em Araguaína pode ter contribuído para a ausência de significância entre a infecção por B. canis e todas as variáveis estudadas ${ }^{14}$. A ocorrência de abortos em cadelas já foi constatado como fator associado à infecção por $B$. canis $^{13}$, no entanto essa variável não foi aqui estudada.

A ausência de animais positivos à prova confirmatória para diagnóstico da infecção por $B$. abortus pode estar ligada ao baixo risco de infecção a que os animais estavam submetidos, considerando-se que foram pesquisados animais da zona urbana. Isso dificulta o contato dos cães com a principal fonte de in-

Tabela 1 - Animais positivos e negativos para a infecção por Brucella canis em cães do município de Araguaína, Tocantins, segundo os possíveis fatores de risco associados à brucelose canina e à probabilidade de ocorrência ao acaso $(\mathrm{P})$ na análise univariada

\begin{tabular}{|c|c|c|c|}
\hline Fator de risco & Positivo & Negativo & $\mathbf{P}$ \\
\hline Idade & & & 0,182 \\
\hline Até 1 ano & $45 / 98$ & $53 / 98$ & \\
\hline 2 a 3 anos & $78 / 159$ & $81 / 159$ & \\
\hline Acima de 3 anos & $10 / 32$ & $22 / 32$ & \\
\hline Castração & & & 0,558 \\
\hline Sim & $6 / 11$ & $5 / 11$ & \\
\hline Não & $86 / 189$ & $103 / 189$ & \\
\hline Acesso à rua & & & 0,439 \\
\hline Sim & $69 / 159$ & $90 / 159$ & \\
\hline Não & $74 / 155$ & $81 / 155$ & \\
\hline Contato com animais & & & 0,385 \\
\hline Sim & $70 / 150$ & $80 / 150$ & \\
\hline Não & $30 / 74$ & $44 / 74$ & \\
\hline Filhotes & & & 0,908 \\
\hline Sim & $39 / 92$ & $53 / 92$ & \\
\hline Não & $26 / 60$ & $34 / 60$ & \\
\hline Acasalamento & & & 0,625 \\
\hline Sim & $63 / 144$ & $81 / 144$ & \\
\hline Não & $74 / 159$ & $85 / 159$ & \\
\hline
\end{tabular}


fecção de B. abortus para os carnívoros, material de aborto ou parto de vacas infectadas, cuja prevalência é alta no Estado do Tocantins ${ }^{26,27}$.

Assim, o presente estudo permite concluir que não houve animais infectados por $B$. abortus na população estudada e que a infecção por B. canis está altamente disseminada em cães do município de Araguaína, Tocantins.

\section{Referências}

1. CARMICHAEL, L. E.; JOUBERT, J. C. Transmission of Brucella canis by contact exposure. Cornell Veterinary, v. 78, n. 1, p. 63-73, 1988.

2. WANKE, M. M. Canine brucellosis. Animal Reproduction Science, v. 82, n. 83, p. 195-207, 2004.

3. MIRANDA, K. L.; COTTORELlO, A. C. P.; POESTER, F. R.; LAGE, A. P. Brucelose canina. Cadernos Técnicos de Veterinária e Zootecnia, n. 47, p. 66-82, 2005.

4. CARMICHAEL, L. E. Abortion in 200 beagles (New Report). Journal of American Veterinary Medical Association, v. 149, n. 15, p. 1126, 1966.

5. WALD, V. B.; FERNANDES, J. C. T. Sorologia da brucelose canina no município de Porto Alegre, RS. Arquivos da Faculdade de Veterinária UFRGS, v. 4, n. 5, p. 92-95, 1976.

6. GERMANO, P. M. L.; VASCONCELLOS, S. A.; ISHIZUKA, M. M.; PASSOS, E. C.; ERBOLATO, E. B. Prevalência de infecção por Brucella canis em cães da cidade de Campinas - SP, Brasil. Revista da Faculdade de Medicina Veterinária e Zootecnia da Universidade de São Paulo, v. 24, n. 1, p. 27-34, 1987.

7.SCHLEMPER, S. R. M.; VAZ, A. K. Inquérito sorológico para brucelose canina por Brucella canis na região do planalto catarinese, Brasil. Revista Brasileira de Medicina Veterinária, v. 12 , p. 8-12, 1990.

8. MELO, S. M. B.; AGUIAR, P. H. P.; NASCIMENTO, R. M.; FREIRE, S. M. Avaliação sorológica por imunodifusão em gel de ágar para diagnóstico de Brucella canis em cães no distrito de Monte Gordo - Camaçari - Bahia. Arquivos da Escola de Medicina Veterinária da UFBA, v. 19, n. 1, p. 119-127, 1998.

9. MEGID, J.; BRITO, A. F.; MORAES, C. C. G.; FAVA, N.; AGOTTANI, J. Epidemiological assessment of canine brucellosis. Arquivo Brasileiro de Medicina Veterinária e Zootecnia, v. 51, n. 5, p. 439-440, 1999.

10.SOUZA, L. A.; VIANA, R. C. A.; MICHALICK, M. S. M.; REIS, J. K. P.; LAGE, A. P. Prevalência de infecção por Brucella canis em Belo Horizonte - MG. Revista Brasileira de Medicina Veterinária, v. 24, n. 3, p. 127-131, 2002.

11.MORAES, C. C. G.; MEGID, J.; SOUZA, L. C.; CROCCI, A. J. Prevalência da brucelose canina na microrregião da serra de Botucatu, São Paulo, Brasil. Arquivos do Instituto Biológico, v. 69, n. 2, p. 7-10, 2002.

12.ALMEIDA, A. C.; SANTORELLI, A.; BRUZADELLI, R. M. Z.; OLIVEIRA, M. M. N. F. Soroepidemiologia da brucelose canina causada por Brucella canis e Brucella abortus na cidade de Alfenas, MG. Arquivos Brasileiros de Medicina Veterinária e Zootecnia, v. 56, n. 2, p. 275-276, 2004.

\section{Agradecimentos}

Este estudo foi financiado pela Fundação de Amparo à Pesquisa do Estado de Minas Gerais - Fapemig, (Belo Horizonte, Brasil), FEP-MVZ Coordenação Preventiva (Belo Horizonte, Brasil) e Conselho Nacional de Desenvolvimento Científico e Tecnológico - CNPq (Brasília, Brasil). EMSD, CDT e APL foram apoiados por bolsas do CNPq.

13.VASCONCELOS, R. T. J.; ALVES, C. J.; CLEMENTINO, I. J.; ARAÚJO NETO, J. O.; ALVEZ, F. A. L.; BATISTA, C. S. A.; BERNARD, F; SOTO, F. R. M.; OLIVEIRA, R. M. de; AZEVEDO, S. D. de. Soroprevalência e fatores de risco associados à infecção por Brucella canis em cães da cidade de Campina Grande, estado da Paraíba. Revista Brasileira de Saúde e Produção Animal, v. 9, n. 3, p. 436-442, 2008.

14.NOORDHUIZEN, J. P. T. M.; FRANKENA, K.; VANDERHOOFD, C. M.; GRAAT, E. A. M. (Ed.). Application of quantitative methods in veterinary epidemiology. Wageningen: Wagenigen Press, 1997. 445 p. (Tropical Animal Health and Publication, v. 30, n. 12).

15. ALTON, G. G.; JONES, L. M.; ANGUS, R. D.; VERGER, J. M. Techniques for the brucellosis laboratory. Paris: INRA, 1988, $190 \mathrm{p}$.

16.NIELSEN, K.; LIN, M.; GALL, D.; JOLLEY, M. Fluorescence polarization immunoassay: detection of antibody to Brucella abortus. Methods, v. 22, n. 1, p. 71-76, 2000.

17.BRASIL. Ministério da Agricultura, Pecuária e Abastecimento. Programa Nacional de Controle e Erradicação da Brucelose e Tuberculose. Manual técnico do Programa Nacional de Controle e Erradicação da Brucelose e da Tuberculose - PNCEBT. Brasília: MAPA/ DSA/DSA, 2006. 184 p.

18.SAMPAIO, I. B. M. Estatística aplicada à experimentação animal. 2. ed. Belo Horizonte: Fundação de Ensino e Pesquisa em Medicina Veterinária e Zootecnia, 2002. 265 p.

19.DEAN, A. G.; DEAN, J. A.; COULOMBIER, D. EPI INFO, version $6.02 \mathrm{~b}$ : a word processing, database and statistics program for epidemiology on micro-computers. Atlanta, Georgia: Center for Disease Control, 1995.

20.MINHARRO, S.; COTTORELLO, A. C. P.; MIRANDA, K. L.; STYNEN, A. P. R.; ALVES, T. M.; LAGE, A. P. Diagnóstico da brucelose canina: dificuldades e estratégias. Revista Brasileira Reprodução Animal, v. 29, n. 3/4, p. 167-173, 2005.

21.JOHNSON, C. A.; WALKER, R. D. Clinical signs and diagnosis of Brucella canis infection. Compendium on Continuing Education, v. 14 n. único, p.763-772, 1992.

22. CARMICHAEL, L. E., SHIN, S. J. Canine brucellosis: a diagnostician's dilemma. Seminars in Veterinary Medical and Surgery (Small Animals), v. 11, n. 3, p. 161-165, 1996.

23.KEID, L. B.; SOARES, R. M.; VASCONCELLOS, S. A.; MEGID, J.; SALGADO, V. R.; RICHTZENHAIN, L. J. Comparison of agar gel immunodiffusion test, rapid slide agglutination test, microbiological culture and PCR for the 
diagnosis of canine brucellosis. Research in Veterinary Science, v. 86, n. 1, p. 22-26, 2009.

24.AZEVEDO, S. S.; VASCONCELLOS, S. A.; ALVES, C.J.; KEID, L. B.; GRASSO, L. M. P. S.; MASCOLLI, R.; PINHEIRO, $\mathrm{S}$. Inquérito sorológico e fatores de risco para a brucelose por Brucella canis em cães do município de Santana de Parnaíba, Estado de São Paulo. Pesquisa Veterinária Brasileira, v, 23, n. 4, p. 156-160, 2003.

25.PORTO, W. J. N.; PINHEIRO JUNIOR, J. W.; MOTA, R. A. Associação entre distúrbios reprodutivos e anticorpos anti-Brucella sp em cães atendidos em clínicas particulares da cidade de Maceió-AL. Revista Brasileira de Ciência Veterinária, v. 15, n. 1, p. 6-9, 2008.

26.CARMICHAEL, L. E. Brucella canis. In: NIELSEN, K.; DUNCAN, J. R. Animal brucellosis. Boca Raton: CRC Press, 1990. p. 335-350.

27.OGATA, R. A.; GONCALVES, V. S. P.; FIGUEIREDO, V. C. F.; LÔBO, J. R.; RODRIGUES, A. L.; AMAKU, M.; FERREIRA, F.; FERREIRA NETO, J. S.; DIAS, R. A. Situação epidemiológica da brucelose bovina no Estado do Tocantins. Arquivo Brasileiro de Medicina Veterinária e Zootecnia, v. 61 , p. 126-134, 2009. Suplemento, 1. 